\title{
Research on the Elite Education under the Pluralization of Higher Education and Its Quality Evaluation
}

\author{
Han Yu, Zhang Jianglong, and Ma Qishuang
}

\begin{abstract}
In the face of the urgent need of the top innovative talents in our country and the intensification of diversification trend of higher education, the role of the elite education that focuses on cultivating elite talents, which is a form of higher education in the research and practice of top-notch innovative talents cultivation system, has been re-emphasized. Many colleges and universities are vigorously promoting elite education research, and have set up their own elite education system, to carry on the elite talent-training attempt. At the same time, to build a system of evaluating the quality of education that matches the cultivation of elite talents has become one of the most important topics in the current higher education research. This article briefly discusses the significance of strengthening elite education under the trend of higher education diversification, and the theoretical school and the development trend of educational evaluation, and tentatively discusses the framework of quality evaluation system regarding elite education.
\end{abstract}

Index Terms-Higher education, elite education, quality evaluation.

\section{INTRODUCTION}

Under the current international situation, the competition for comprehensive national strengths is about the competition for talents, which makes the human resources the most important strategic resource in national development. Especially, the elite in all social sectors has been regarded as the core competency of a country. At present, the higher education has been basically taken to the general public in China. However, if we want to make China a country rich in human resources and comprehensively enhance China's competence in international community, we need to put the nurturing of top innovative talents high on our higher education agenda.

In China, higher education has experienced a period of rapid development, entering into the stage of popularization from the traditional elite education, which equips China with the largest higher education system in the world and helps improve the nationals' literacy level. Nonetheless, the development of high-quality higher education and higher vocational education remains sluggish. In this regard, it is necessary to develop diversified higher education and improve higher education structure with a view to resolving the problems brought by the popularization of higher education and enhancing the education quality [1].

In the face of the urgent need of the top innovative talents in

Manuscript received January 15, 2019; revised May 21, 2019.

The authors are with Beihang University, Beijing, 100083, China (e-mail: yhan@buaa.edu.cn, zhang111330@buaa.edu.cn, qsma304@buaa.edu.cn). our country and the intensification of diversification trend of higher education, the role of the elite education that focuses on cultivating elite talents, which is a form of higher education in the research and practice of top-notch innovative talents cultivation system, has been re-emphasized. Many colleges and universities are vigorously promoting elite education research, and have set up their own elite education system, to carry on the elite talent-training attempt. At the same time, to build a system of evaluating the quality of education that matches the cultivation of elite talents has become one of the most important topics in the current higher education research. This article briefly discusses the significance of strengthening elite education under the trend of diversification of higher education and tentatively discusses the framework of quality evaluation system regarding elite education.

\section{THE Role OF ELITE EDUCATION UNDER THE CURRENT SITUATION}

\section{A. The Diversification Trend of Higher Education}

Since 1990s, higher education has been developed and scaled up vigorously in China, realizing the transformation from elite education to popularization of education. However, there are still problems: on one hand, the current development of higher education still lags behind the increasing educational needs of students; on the other hand, because of the scarcity of high-quality higher education resources and the underdeveloped higher vocational education, the educational structure lacks diversity, the talent training system is imbalanced and the talents which represent the core competence of building an innovative country and the senior technical personnel which is needed in high-tech industries during the process of industrialization are falling short of the huge needs. Therefore, it's established that higher education should be diversified and this has already become the development trend of higher education. Specifically, institutions of higher education will be classified based on the resource advantages and training targets and then related development strategies will be generated. At the same time when the higher education is being taken to the general public vigorously, more efforts need to be paid to enhance the elite higher education represented by the research universities and higher vocational education which focuses on training applied and technical talents. Eventually, on the basis of the diversification of higher education, the diversified development of talents will be realized and the diversified needs of talents in response to the national development will be satisfied [2]. 


\section{B. The Significance of Developing Elite Education}

The characteristic of traditional higher education lies in its objective of nurturing elites. However, during the popularization of higher education in China, the unreasonable and imbalanced distribution of educational resources results into the fact that less attention was paid to the elite education, impeding the sound development of higher education.

Elite education, an important part of the diversification of higher education, needs to be reemphasized. The reasons are threefold. Firstly, it is of necessity to develop elite education with the purpose of sustainable and coordinated development of higher education. If we want to realize the diversification and coordinated development of higher education during its popularization stage, it is a must to coordinate various educational institutions and forms and achieve the integration among educational scale, quality, structure and effectiveness. Elite education plays an important role in helping higher education lead the way in nurturing talents. Only by coordinating elite education and other forms of education can we give full play to the role of higher education. Secondly, it is of necessity to develop elite education with the purpose of fulfilling the country's needs of diversified talents. With the rapid development of society and economy in China, there is a growing need for a great variety of talents, with a focus on both new leading innovative talents carrying out basic research, applied research and high-tech research and engineering technicians and senior technicians with certain literacy, which decides that the training methods and structures of higher education should have different and clear layers, therefore, attentions should be equally paid to elite education, popular education and vocational education. Thirdly, it is of necessity to develop elite education with the purpose of promoting the development of human society. The leapfrog development of human society requires the elites. Talents stand for people's tribute to the past and expectation of the future from the past to the present, from the long-term fighting the nature to the rapid development of human society. Hence, there is no doubt that elite education does exist for reasons.

With the increasing needs of top innovative talents and the diversification trend of higher education, there is a stronger voice in protecting and strengthening elite education. During the popularization of higher education, the core role of elite education in research universities has been given full play. Many institutes of higher education also established their own Elite Nurturing Special Zone, studying and practicing the methods of nurturing elites under the current situation of diversification and popularization of higher education and achieving a great number of results, which also provides us with new perspective of recognizing elite education.

\section{DEVELOPMENT AND CURRENT SitUATION OF HigheR EDUCATION QUALITY ASSESSMENT}

Educational evaluation is a process of factual analysis and value judgment of educational practice activities based on certain goals and standards. The assessment history and evaluation system of higher education varies from country to country due to differences in their political, economic, cultural, scientific, and educational systems. In general, modern education assessment has undergone several typical stages of measurement, description, judgment, and construction in the development process. The evolution of education evaluation theory mainly includes three schools, as follows:

1) Target School: This is considered to be the origin of educational evaluation. It originated from the "eight years of research" in the United States in the 1930s. Ralph Tyler was called as the "father of educational evaluation" because of his pioneering contribution to the development of educational evaluation in the "eight years of research". Taylor's doctrine emphasizes the importance of educational goals and believes that the focus of the assessment should be on the outcome of student learning [3].

2) Information School: Lee J. Cronbach defines educational evaluation as the decision to collect and use information to complete educational programs. This is not the same as Tyler's theory. Taylor's goal-oriented assessment is more inclined to the overall evaluation after the event, and Cronbach prefers to improve the curriculum through educational evaluation [4].

3) Value school: Scriven believes that educational evaluation is ultimately attributed to value judgment. Educational evaluation is not just a process of determining facts and their effects, but more that, educational evaluation must draw a specific type of conclusion, so he defines evaluation as the process of determining merit, value, and meaning. Besides, he for the first time uses Valuing to represent value judgments, not the evaluations used by Taylor, nor the judgments with unclear meanings [5].

The views of the target school, the information school, and the value school reflect the differences in the understanding of the concept of educational evaluation concepts by some of the founding scholars [6]. In summary, there are four main points: First, how to look at the status of the target in the evaluation of education, that is, whether the assessment is a target-referenced activity or a target-free activity; Second, how to look at the status of information provision and value judgment in the assessment, that is, whether the assessment is essentially providing information or making value judgments; Third, the clients of the assessment, that is, whether the assessment is for decision makers or a wider range of stakeholders; Fourth, who makes value judgments. It is made by the value judgment evaluator alone, by the evaluator and the stakeholders, or by the stakeholders alone.

The evaluation theories, methods and models at each stage undoubtedly have the meaning of their own era, and have played an important historical role in safeguarding and improving the quality of education. Even today, they still play an active role in various fields. However, with the transformation and development of the economy and society, the concepts and methods of higher education and education evaluation have undergone some changes, which can be summarized as the following three aspects:

1) The subject of educational evaluation has become diversified. The main body of traditional education evaluation is the government while the indicators of 
evaluation often reflect the government's preferences. Now, this situation has changed a lot, and the relevant people of modern social education (including educators, educatees, managers and social stakeholders) can conduct educational evaluation, and the evaluation indicators are becoming richer as well.

2) The cycle of educational assessment has become routine. The traditional educational evaluation is often conducted by the government every few years, and the timeliness of educational evaluation is low. Now the cycle of education evaluation is gradually shortened, the assessment begins to change to daily, the feedback time of evaluation is shortened, and the timeliness of education evaluation is improved.

3) The value of educational assessment has become diversified. The diversification of the subject of education evaluation also brings about the diversification of the value of education evaluation. Different education stakeholders pay attention to different aspects of modern educational development, thus promoting a more comprehensive development of education and continuous improvement of the education quality.

The most typical example is that with the development of information technology, many countries have included monitoring and evaluation in the scope of educational evaluation, which is used to obtain a large amount of educational data, and has made great progress. In the United States, the National Center for Education Statistics (NCES) affiliated to Institute of Educational Science of the U.S. Department of Education has accumulated a large amount of monitoring data, systematically carried out survey statistics and assessments of various types of educational programs, and served in educational quality monitoring and educational decision-making. Besides, the US National Assessment of Educational Progress (NAEP) has been monitoring and evaluating science, technology, engineering, and mathematics (STEM) for more than 30 years [7]. The United Kingdom has also carried out monitoring and evaluation of higher education. The employment status of college graduates, which is jointly carried out by the Higher Education Fund Committee and the Higher Education Statistics Department, has been monitored for more than 20 years [8]. The monitoring content is comprehensive and detailed. China has also written monitoring assessments into relevant documents and conducted explorations.

\section{The CONSTRUCTION OF QuALity EVALUATION SyStem REGARDING ELITE EDUCATION}

Higher education evaluation is a process of objectively appraising all aspects of higher education, serving as the main basis for the quality evaluation of higher education. The diversification trend of higher education calls for the diversification trend of higher education evaluation standards, which means that various education forms need to establish their respective evaluation standards to implement the appraisal, supervision and guidance [9] and so does the elite education.

\section{A. The Significance of Quality Evaluation System Regarding Elite Education}

It is of great importance for elite education, an important constitution of diversified higher education, to put in place the quality evaluation system regarding elite education on the basis of the original higher education quality evaluation system, which will help improve and complement the whole higher education quality evaluation system.

Firstly, the quality evaluation system regarding elite education provides a good measurement for the elite education. Being similar to the usual evaluation system, it is sound for the quality evaluation system regarding elite education to evaluate the participants. By using the sound indicator system to comprehensively examine the implementation and outcomes of elite education, this system can relatively objectively demonstrate the reality of elite education [10]. In terms of elite education that has been reviewed during the popularization of higher education, the public is both optimistic and confused about it. Hence, it is of practical significance to know about the actual results of elite education in real time.

Secondly, the quality evaluation system regarding elite education can help regulate the development of elite education in return. Evaluation results play an important role in helping reform and improve the methods and models of elite education. Based on the results of each indicator, the education institutes will be able to objectively judge whether currently the distribution of educational resources is sound, the teaching methods are of obvious effect, students' innovation ability has been improved, comprehensive quality of students has been enhanced, the society accepts it, etc. After this, the education institutes can reallocate the education resources, improve the teaching methods, enhance students' comprehensive quality, raise the social acceptance and restudy the whole training system and push forward the reform and development of elite education when necessary.

Thirdly, the quality evaluation system regarding elite education can act as a powerful supervisor of the elite education development. Elite education has an explicit educational target that is to nurture leading innovative talents. The quality evaluation system regarding elite education can coordinate the teaching methods, teaching effectiveness and fundamental goals of education and prevent elite education from veering off the right track with the sound indicator system and objective and comprehensive evaluation results. Meanwhile, as a representative of educational management, the quality evaluation system can help regulate the allocation of resources within the educational system, motivate the educators to tap their potential and improve the teaching and management, further ensuring the healthy and highly efficient development of elite education.

Nowadays, the importance of elite education has been widely recognized and the whole society pays great attention on the quality of elite education. Without a quality evaluation system, elite education will be an open-loop system, lacking the ability of operating in a stable and normal manner. Only by establishing a quality evaluation system regarding elite education that helps create a closed-loop system can elite education develop in a healthy way. 


\section{B. Design Principles of Quality Evaluation System Regarding Elite Education}

When designing the quality evaluation system regarding elite education, the following principles should be followed.

Firstly, setting clear objectives. The establishment of the quality evaluation system regarding elite education should be based on the objectives of elite education and embody the requirements of the elite education while this system should be relatively stable and consistent during the nurturing of talents. Therefore, when establishing this system, we need to stand from the present and look into the future, integrating the short-term objectives with long-term ones. When designing the indicator system, we need to not only focus on specific elements, precisely reflecting the performance of elite education that bears the responsibility of nurturing talents, but also provide objective and comprehensive appraisals of all aspects of elite education, including development orientation, development speed and development potential, which would serve as a basis for the future development strategic plans, a reference for the educational reforms and guidance for the development of elite education.

Secondly, adopting an objective and holistic approach. When designing the quality evaluation system regarding elite education, we need to follow the objective principle, establish the indicator system in a well-conceived way, and draw experience from the outstanding achievements of education from home and abroad and current indicator system of education evaluation. Besides, we need to carry out in-depth research based on the reality and then establish the quality evaluation system regarding elite education in an objective and rigorous manner [11]. During the formulation of indicator system, we should try our best to comprehensively integrate the requirements of objectives subject to evaluation, ensuring the consistency between indicator design and evaluation objects and the compatibility and independence of all the indicators within the system, with a view to reducing the distortion and increasing the reliability and validity. Meanwhile, different indicators should be attached with different weights according to their importance so as to make the whole evaluation indicator system well structured.

Thirdly, combining quantitative methods with qualitative methods. The evaluation object of the quality evaluation system regarding elite education is elite education. In terms of elite education, there exist objective factors of high comparability that can be measured by numbers and relatively subjective and ambiguous factors. Hence, it is incomprehensive to evaluate elite education by solely using qualitative methods or quantitative methods. In this regards, these two kinds of methods need to be integrated organically. On one hand, through collecting data and using mathematics ways to go through quantitative calculations, we can acquire plenty of precise data as basis and draw conclusions concerning quantitative evaluation. On the other hand, there should be qualitative indicators that can help make qualitative judgments on unquantifiable evaluation objects by using observation, interview, comprehensive analysis, etc. By doing this, we can grasp a macro understanding of development trend of elite education so as to reach the purpose of evaluation.
Fourthly, designing in a user-friendly way. The user-friendly design of the elite education evaluation system embodies dual meanings: the first is measurability. When the indicator system is formulated, the higher-level indicators are more generalized, and the lower-level indicators are more micro-specific. However, the definition and description of the indicators should be expressed as much as possible using behavioral and operational language, so that they can be directly measured and evaluated. Improper expression can affect measurability and thus greatly affect the assessment. The second is operability. The indicator system is required to select highly representative and convincing indicators under the premise of comprehensive coverage of evaluation factors, improve generalization, reduce items and try to be focused and simple. At the same time, the information involved in the indicator system is easily obtained and quantified. The method is as simple as possible to avoid cumbersome formulas and operations.

\section{Design Ideas of Quality Evaluation System Regarding Elite Education}

Evaluation objects decide on evaluation programs and sequentially on the composition of the evaluation indicator system. Therefore, the basic designing idea of the evaluation system is to establish the evaluation indicator system by analyzing the evaluation objectives. The objective of elite education is to nurture leading innovative talents, which can be boiled down the educational process and educational outcomes. For these two aspects, they have their respective evaluation programs. For example, the educational process consists of substantial contents, including talent cultivation philosophy, cultivation mechanism and management, teaching fund and hardware facilities, the setting of curriculum training programs and staffing, experiment teaching and practical teaching, investment and construction of innovative practice base, teaching contents and methods, innovation and scientific research ability, and academic environment of teachers and scientific research guidance for students. The educational outcomes are made up of several aspects, including students' ethical standards, psychological quality, theoretical quality of foundation subjects, professional theoretical quality, innovation and practical ability, and social assessment. These items correspond to their own specific goals and implementation methods, and can be divided into more specific and subtle evaluation indicators. These numerous evaluation indicators form an organic whole, thus constructing the entire elite education evaluation system.

\section{CONCLUSION AND OUTLOOK}

Although the objectives and methods of elite education differentiate from each other slightly in different times, the law of development of human society and the objectives of higher education make elite education necessary and important. During the exploration of models and methods of elite education, ensuring the quality of elite education needs to be prioritized. Without sound evaluation system, there will be no sound management and the guiding role of quality evaluation system should be emphasized. This article analyzes the orientation of elite education in the current 
situation, expounds the significance of constructing the elite education quality assessment system, and clarifies that the quality assessment system design should follow the principles of clear objectives, objective comprehensiveness, quantitative-qualitative combination and easy operation, hence the initial design ideas is proposed. However, the contents just briefly discusses the framework of quality evaluation system regarding elite education, but in practice, the principles illustrated above need to be followed and more efforts should be given to the research, study and thorough categorization. By doing so, a comprehensive quality evaluation system regarding elite education that fits the national development needs will be established eventually, which could propel the elite education in China to adapt to the development needs and help nurture new leading innovative talents.

\section{REFERENCES}

[1] D. G. Yang, "Popularization, diversification and quality assurance of higher education - Summary report of the 6th annual academic conference of the national higher education research association," Journal of Higher Education, vol. 22, pp. 3-6, July 2001.

[2] Z. G. Liu, "Mass education, elite education and research universities," China Higher Education Research, vol. 5, pp. 4-6, 2006.

[3] R. W. Tyler, Basic Principles of Curriculum and Instruction, University of Chicago Press, 1950.

[4] L. J. Cronbach, "Evaluation for course improvement," Teachers College Record, 1963, vol. 64, no. 8, pp. 672-683.

[5] M. Scriven, The Logic of Evaluation, Edge press, 1981.

[6] Z. J. Wang, The Theory and Method of Monitoring Evaluation in Higher Education, China Science Publishing, 2017.

[7] H. Y. Xu, "US STEM education monitoring indicator system based on big data: Analysis and enlightenment," Educational Measurement and Evaluation, no. 09, 2014.

[8] Z. R. Wang and C. Dong, "A study on the monitoring operating mechanism of British university graduates' employment situation," 2012.
[9] Q. D. Wu, "The construction and improvement of China's higher education evaluation system," Research in Education Development, vol. 3, pp. 38-41, 2009.

[10] J. Z. Xiao, X. J. Chen, and X. X. Jia, "Diversification of higher education evaluation," Higher Education Exploration, vol. 1, pp. $13-15,2013$

[11] B. L. Zhong and H. T. Zhou, "New characteristics, impacts and implications of the development of international quality evaluation of higher education," Journal of Higher Education, vol. 30, no. 1, pp. 1-5, Jan. 2009.

Copyright $\odot 2019$ by the authors. This is an open access article distributed under the Creative Commons Attribution License which permits unrestricted use, distribution, and reproduction in any medium, provided the original work is properly cited (CC BY 4.0).

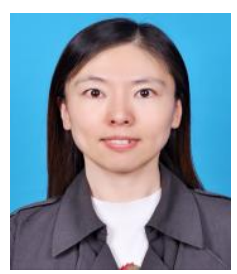

Han Yu was born in Shandong, China on June 29, 1981. She got the doctor degree of management in 2016 at Beihang University, Beijing, China.

She is now working as a vice dean in Shen Yuan Honors College, Beihang University, China. Her major interested field of study is management of higher education.

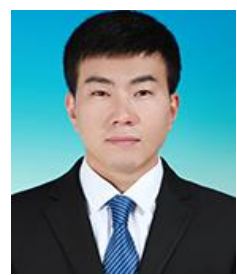

Zhang Jianglong was born in Gansu, China on January 8, 1990. He got the doctor degree of engineering in 2018 at Beihang University, Beijing, China.

$\mathrm{He}$ is now working as a student counselor in Shen Yuan Honors College, Beihang University, China. His major interested field of study is management of higher education.

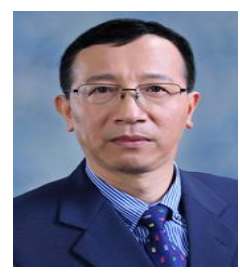

Ma Qishuang was born in Heilongjiang, China on February 23, 1962. He got the doctor degree of electrical engineering in 1994 at Xi'an Jiaotong University, Xi'an, China.

$\mathrm{He}$ is now working as the dean of Shen Yuan Honors College, Beihang University, China. His major interested field of study is management of higher education. 